\title{
Endemic atypical parkinsonism
}

\section{Authors:}

Laura Silveira-Moriyama ${ }^{1,2}$ and Andrew J. Lees ${ }^{3}$.

\section{Affiliations:}

1. Universidade Nove de Julho, Sao Paulo, Brazil

2. Universidade Estadual de Campinas, Campinas, Brazil

3. UCL Institute of Neurology, University College London, London, UK

\section{Corresponding author:}

Prof Laura Silveira Moriyama, Posgraduate Program in Medicine, Universidade Nove de Julho (Uninove), 239-245 Vergueiro, Sao Paulo, SP, Brazil. 01504-000. Laura.moriyama@ucl.ac.uk

Word count: 598 words, 07 references

\section{Manuscript}

Lannuzel et al ${ }^{1}$ report on 305 consecutive patients who presented to the departments of neurology in two of the French Antilles, Guadeloupe and Martinique, with probable neurodegenerative Parkinsonism over a four-year period (2012-2016). Although the study is cross-sectional, the cohort in Guadeloupe has been followed-up since 1995. In the first study from Guadeloupe Caparros-Lefebre et al ${ }^{2}$ diagnosed only 22 (36\%) of the patients presenting with Parkinsonism as Parkinson's disease (PD). The remaining patients had atypical Parkinsonism with some clinical features rarely found in PD: 31 were diagnosed with probable progressive supranuclear palsy (PSP), 30 had an unclassifiable Parkinsonism, and four had atypical parkinsonism associated with motor neuron disease.

A high rate of atypical parkinsonism, dementia and motor neuron disease (lytico-bodig) had been earlier reported in Guam. The prevalence of this disorder has decreased steadily over the last few decades since the disorder was first recognised in the nineteen sixties but the explanation for this remains unclear ${ }^{3}$. The remarkable finding in Lannuzel and colleagues new report relate to the identification of a new cluster of atypical Parkinsonism on Martinique identical to that already reported on Guadeloupe.

Abundant three and four repeat tau positive Alzheimer's-like neurofibrillary tangles on a background of severe neuronal loss in cortical and subcortical regions are the commonest reported pathological finding in patients with Parkinsonism-dementia of Guam. More recently TDP43 positive inclusions have also been identified $^{4}$. TDP43 proteinopathy is a common finding MND and some types of frontotemporal lobar degeneration without tau pathology ${ }^{5}$. One MND patient from Guadaloupe who came to autopsy in $1999^{2}$ had spongiosis on the prefrontal cortex, pallor of the pyramidal tracts and severe neuronal loss and gliosis in the anterior horns. There were no Lewy bodies or neurofibrillary tangles, but immunohistochemistry for TDP-43 was not available at that time. Tau positive inclusions were found in three Guadaloupean atypical parkinsonians who came to autopsy before $2002^{6}$. The first of these cases developed parkinsonism aged 53 years and died four years later, having presented supranuclear gaze palsy and parkinsonism with falls after the first year of disease. He had nigral degeneration and spongiosis of the cortex, with widespread tau positive threads without tufted astrocytes; the patient had hallucinations during early disease but no alpha-synuclein positive inclusions were found. The second patient had dementia and supranuclear gaze palsy within the first year, and later on frequent falls, and at autopsy had nigral degeneration, with sparing of the neocortex, and tau accumulation in extent and localization suggestive of PSP. The third patient who had developed falls and supranuclear gaze palsy within one year of symptoms onset, and later on developed dementia and experienced hallucinations also had tau positive neurofibrially tangles and tufted astrocytes compatible with PSP.

Many of the clinical descriptions of atypical Parkinsonism from Guadeloupe and Martinique resemble PSP-Parkinsonism, Richardson's syndrome, vascular Parkinsonism and even Parkinson's disease presenting later in life. Visual hallucinations in patients not treated with anti-Parkinsonian drugs are very uncommon in PSP but interestingly have been reported on a number of occasions in association with dementia and a PSP like motor phenotype in the French Antilles ${ }^{7}$. In Lannuzel and colleagues study ${ }^{1} 35.7 \%$ of 202 patients with atypical parkinsonism in Guadaloupe and Martinique also presented with motor 
fluctuations/dyskinesias, which is lower than PD (58.6\% of 100 Caribbean PD patients in the study), but a much higher figure than is seen in PSP.

Whether Caribbean parkinsonism will prove to be a distinct clinico-pathological entity will depend on further post mortem and molecular biological and genetic studies. Further work on the Guadeloupe and Martinique cohort may also shed light on the unsolved mystery of lytico-bodig on Guam and other geographical isolates.

\section{REFERENCES:}

1. Lannuzel A, Edragas R, Lackmy A et al. Further evidence for a distinctive atypical degenerative parkinsonism in the Caribbean: a new cluster in the French West Indian island of Martinique. J Neurol Sci, 2018 in press.

2- Caparros-Lefebvre D, Elbaz A. Possible relation of atypical parkinsonism in the French West Indies with consumption of tropical plants: a case-control study. Caribbean Parkinsonism Study Group. Lancet, 1999 ul 24;354(9175):281-6

3 - Steele JC, Caparros-Lefebvre D, Lees AJ, Sacks OW. Progressive supranuclear palsy and its relation to pacific foci of the parkinsonism-dementia complex and Guadeloupean parkinsonism. Parkinsonism Relat Disord. 2002 Oct;9(1):39-54.

4 - Hasegawa M, Arai T, Akiyama $\mathrm{H}$ et al. TDP-43 is deposited in the Guam parkinsonism-dementia complex brains. Brain. 2007 May;130(Pt 5):1386-94. Epub 2007 Apr 17.

5 - Chen-Plotkin AS1, Lee VM, Trojanowski JQ. TAR DNA-binding protein 43 in neurodegenerative disease. Nat Rev Neurol. 2010 Apr;6(4):211-20. doi: 10.1038/nrneurol.2010.18. Epub 2010 Mar 16.

6 - Caparros-Lefebvre D, Sergeant N, Lees A, Camuzat A, Daniel S, Lannuzel A, Brice A, Tolosa E, Delacourte A, Duyckaerts C. Guadeloupean parkinsonism: a cluster of progressive supranuclear palsy-like tauopathy. Brain. 2002 Apr;125(Pt 4):801-11.

7 - Lannuzel A, Höglinger GU, Verhaeghe S et al. Atypical parkinsonism in Guadeloupe: a common risk factor for two closely related phenotypes? Brain. 2007 Mar;130(Pt 3):816-27. Epub 2007 Feb 15. 